\title{
Early and Late Return to Work After Sick Leave: Predictors in a Cohort of Sick-Listed Individuals with Common Mental Disorders
}

\author{
Kerstin Ekberg, Charlotte Wåhlin, Jan Persson, Lars Bernfort and Birgitta Öberg
}

\section{Linköping University Post Print}

\section{Tweet}

N.B.: When citing this work, cite the original article.

The original publication is available at www.springerlink.com:

Kerstin Ekberg, Charlotte Wåhlin, Jan Persson, Lars Bernfort and Birgitta Öberg, Early and Late Return to Work After Sick Leave: Predictors in a Cohort of Sick-Listed Individuals with Common Mental Disorders, 2015, Journal of occupational rehabilitation, (25), 3, 627-637. http://dx.doi.org/10.1007/s10926-015-9570-9

Copyright: Springer Verlag (Germany) http://www.springerlink.com/?MUD=MP

Postprint available at: Linköping University Electronic Press http://urn.kb.se/resolve?urn=urn:nbn:se:liu:diva-121301 
Early and late return to work after sick leave - predictors in a cohort of sick-listed individuals with common mental disorders

Kerstin Ekberg ${ }^{1,2}$, Charlotte Wåhlin ${ }^{3,4}$, Jan Persson ${ }^{5}$, Lars Bernfort ${ }^{5}$, Birgitta Öberg ${ }^{6}$

${ }^{1}$ National Centre for Work and Rehabilitation, Department of Medicine and Health, Linköping

University, Linköping, Sweden

${ }^{2}$ Helix Vinn Excellence Centre, Linköping University, Linköping, Sweden

${ }^{3}$ Intervention and Implementation Research Unit, Institute of Environmental Medicine, Karolinska

Institutet, Stockholm, Sweden

${ }^{4}$ Occupational and Environmental Medicine, Department of Clinical and Experimental Medicine,

Linköping University, Sweden

${ }^{5}$ Division of Health Care Analysis, Department of Medicine and Health, Linköping University,

Linköping, Sweden

${ }^{6}$ Division of Physiotherapy, Department of Medicine and Health, Linköping University, Linköping,

Sweden

Author contact: Professor Kerstin Ekberg, National Centre for Work and Rehabilitation, Department of Medicine and Health, Linköping University, 58183 Linköping, Sweden. Tel: +4670 6621458.

Email: kerstin.ekberg@liu.se 


\begin{abstract}
Objectives: The study aims to identify individual and workplace factors associated with early return to work [RTW] - defined as within 3 months - and factors associated with later RTW - between 3 and 12 months after being sick-listed - in a cohort of newly sick-listed individuals with common mental disorders.
\end{abstract}

Methods: In a prospective cohort study, a cross-sectional analysis was performed on baseline measures of patients granted sick leave due to common mental disorders. A total of 533 newly sicklisted individuals fulfilled the inclusion criteria and agreed to participate. A baseline questionnaire was sent by post within three weeks of their first day of certified medical sickness; 354 (66\%) responded. Those who were unemployed were excluded, resulting in a study population of 319 individuals. Sick leave was recorded for each individual from the Social Insurance Office during one year. Analyses were made with multiple Cox regression analyses.

Results: Early RTW was associated with lower education, better work ability at baseline, positive expectations of treatment and low perceived interactional justice with the supervisor. RTW after three months was associated with a need to reduce demands at work, and turnover intentions.

Conclusions: Early RTW among sick-listed individuals with common mental disorders seems to be associated with the individual's need to secure her/his employment situation, whereas later RTW is associated with variables reflecting dissatisfaction with work conditions. No health measures were associated with RTW. The study highlights the importance of considering not only health and functioning, but also workplace conditions and relations at the workplace in implementing RTW interventions.

Key-words: common mental disorders; return to work; work conditions; sick leave duration 


\section{Introduction}

The prevalence of sick-leave due to mental disorders is increasing in Sweden, at present mental disorders account for $44 \%$ of all sick-listed. Increases are in particular seen in the lower middle age and among females [1]. Employees with mental disorders have an increased risk of long-term sick leave [2, 3], and disability pensioning [4] compared with other groups. It is therefore important to prevent the transition of short-term sickness absence into long-term or chronic disability. According to the Organization for Economic Cooperation and Development [OECD], mental health problems account for one third of all new disability benefit claims, and numbers are even higher in some countries, e.g. the Netherlands, United Kingdom and Sweden [5 ]. Common mental disorders are also common among people who are working [5]. These symptoms are associated with reduced functioning and participation at the workplace [6,7] and future sick leave [8]. Presenteeism, i.e. going to work when not in good health, may occur both before sick leave and during a time period after RTW.

\section{Work-related predictors of common mental disorders}

Cognitive and social demands have increased in working life, and work conditions are characterized by high intensity, high work pace, and decentralization of responsibility. Organizational changes have led to new and rapidly changing demands for continuous development of competence, interpersonal skills, flexibility and adaptability. Organizational responses to the growing demand for flexibility are: increasing numbers of temporary employees with reduced job security, divided work schedules, $[9,10]$ and incorporation of work tasks that are perceived as illegitimate [11], e.g. professionals having to take over administrative tasks which other occupational groups could do better .

Hence, organizational changes for improved effectiveness may create adverse work conditions which contribute to the increased prevalence of common mental disorders. In a systematic review, Nieuwenhuijsen et al. [12] found strong evidence that high job demands, low job control, low coworker support, low supervisor support, low procedural justice, low relational justice and a high effort-reward imbalance predicted the incidence of stress-related disorders. Adverse psychosocial workplace conditions affect the onset of depressive symptoms, in particular among employees with a lower socioeconomic position at work [13]. Some authors [14, 15] suggest that specific factors related to human service work, such as emotional demands and role conflicts, are important predictors of burnout. 
Several studies report differences in the period of time until RTW, when comparing different diagnoses [3, 4]; the longest sick leave is reported in connection with depression [7] and anxiety $[16,17]$. Duration and severity of health problems before becoming sick-listed also affects time to RTW [16]. Rehabilitation interventions aiming for symptom recovery do not always lead to restored work ability among sick-listed individuals with common mental disorders [18]. Rather, a number of individual and contextual factors seem to influence actual RTW. In a systematic review, Furlan et al. [19] did not find sufficient support for any workplace interventions that could be recommended as an evidence- based practice for managing depression-related disability, partly due to lack of studies and risk of bias. Using self-reported measures, Wåhlin et al. [20] found that a combination of self-reported clinical and workplace interventions was associated with increased prevalence of RTW within three months, compared with clinical interventions only. These results are in line with the results of the Sherbrook study for sick-listed individuals with musculoskeletal disorders [21], where a combination of clinical and workplace interventions was most effective. This was further supported in a meta-synthesis of qualitative research [22]. Individual factors, as well as social support at the workplace and organization of social and rehabilitation systems affected if and when RTW occurred. Individual characteristics, such as feelings of responsibility and perfectionism and low self-efficacy due to long sick leave, affected the sick-listed individuals' belief in their own capacity. Workplace willingness to reduce working hours, to adapt work conditions, and to provide social support for RTW had an influence on expectations concerning being able to return to work.

Job security seems to influence duration of sick leave. Absence rates are lower among fixed-term employees than among permanent employees [23]. Relations with the supervisor seem to be one mediating factor, as low supervisory support at the workplace has been reported to promote RTW [24], possibly in order to keep the job. Arends et al. [25] found that conflicts with the supervisor predicted recurrent sickness absence. Supervisory behaviour may hence influence both duration of sick-leave and sustainability of work ability. Duration of sick leave due to socioeconomic [SES) position varies between studies and countries. Finnish studies report longer time to RTW for being sick-listed due to depression and with lower SES [26], while Dutch studies found associations between higher SES and longer duration of sick leave [27].

In general, present knowledge indicates that predictors of sick leave as well as predictors of RTW for sick-listed individuals with common mental disorders can be found among a combination of individual and workplace conditions. However, research is still scarce and results are inconclusive. Early RTW is generally considered to be more desirable; for example, in the case of musculoskeletal disorders and pain, three months on sick leave is considered to be a time limit after which rehabilitation interventions become less effective. No similar time limits have been 
discussed for common mental disorders. In the present study we have defined early RTW to be within three months, because this is the time limit set by the Swedish Social Insurance System for being able to return to the present job, while later RTW may mean moving to another job. As a basis for early and adapted rehabilitation and workplace interventions to prevent long-term sick leave among sick-listed individuals with common mental disorders, more knowledge is needed regarding the factors which contribute to RTW in general, as well as to early RTW.

\begin{abstract}
Aim
The study aims to identify individual and workplace factors associated with early RTW (within 3 months) and factors associated with later RTW (between 3 and 12 months) in a cohort of newly sick- listed individuals with common mental disorders.
\end{abstract}

\title{
Research Design and Methods
}

Cases were patients who were granted sick leave due to common mental disorders (CMD) at 39 Primary Healthcare Centres and four Occupational Healthcare Centres in the county of Östergötland, Sweden. Östergötland has about 450,000 inhabitants and is representative of Sweden socioeconomically. Patients seeking primary healthcare are representative of the study population in general.

Subjects were recruited consecutively from June 2008 to December 2009, and their sick leave records were followed for one year after inclusion. Sweden had changes in the regulations for sickleave benefits in 2008 , i.e. before data collection started. The changes involved stricter time regulations for sick-leave with assessments of ability to RTW to the present job within three months, and to take another job with the employer within 6 months. After 6 months on sick-leave the sicklisted person may lose the job. The research team recruited patients by scanning every second week the computerized case records of all patients who obtained a sick-leave certificate at the healthcare centres. Inclusion was based on the ICD-10 main diagnosis in the sickness certificate issued by the physician. Each individual was then recruited by telephone. All patients were provided with written and verbal information about the study before they gave their consent to participate.

The inclusion criteria for participation in the study were: age between 18 and 65 years, ability to communicate in Swedish, and being on sick leave for at least two weeks due to a main diagnosis of CMD, including depression. Exclusion criteria were: sick leave for the same diagnosis in the previous month or sick leave due to a psychiatric diagnosis such as schizophrenia and psychotic disorders, or pregnancy. The study was approved by the Regional Ethics Committee in Linköping. 


\section{Study Population}

A total of 533 sick-listed individuals with common mental diagnoses fulfilled the inclusion criteria and agreed to participate. The included diagnoses were depression (F32-F39), Anxiety (F41), Stress (F43), Burnout (Z73) and “other CMD”. A baseline questionnaire was sent by post to all participants, and $354(66 \%)$ individuals responded to the questionnaire.

\section{Non-response Analysis}

Those included in the cohort were compared with the 179 non-responders for the parameters that were accessible. Non-responders were slightly younger (mean 41 years, SD 11 years) than responders (mean 44 years, SD 11 years, $\mathrm{p}=.097$ ). The proportion of men was higher among nonresponders $(31 \%)$ than among responders $(17 \%, p<.001)$. There was no difference between responders and non-responders in return-to-work rate within 12 months (responders 92\%, nonresponders $89 \%, p=.493$ ), but a higher proportion of responders returned to work within three months (responders 62\%, non- responders 50\%, p=.025). Hence the available cohort had a slight overrepresentation of women and early returners.

\section{Data Collection}

Data were collected from the baseline questionnaires and register data on sick leave were obtained from the Social Insurance Office. The baseline questionnaire was administered within three weeks of the participants' first day of certified medical sickness, which in practice means that they had been on sick leave for about four weeks, as the first week on sick leave does not require a doctor's certificate in Sweden.

\section{Questionnaire}

The baseline questionnaire comprised questions categorised into four blocks: demographic data, health and work ability, personal resources, work conditions and employment situation, in total 171 items.

\section{Demographics}

Demographic variables were age, sex, educational level (nine-year compulsory school, upper secondary school, university), and perceived financial strain (yes/no).

\section{Health}

Generic health-related quality of life (HRQL) was measured using the self-administered fivedimensional instrument EuroQol (EQ-5D) with a three-level response scale. A global score, ranging from -0.59 (worst imaginable state, values below zero correspond to states worse than being dead) to 1.0 (perfect health) can be assigned to the 243 different states attainable from the 
EQ-5D. Global scores were assigned using a tariff based on a general population study in the United Kingdom [28].

Self-rated overall health was measured with the EuroQol visual analogue scale (EQ-VAS) [29]. Ratings are made on a scale ranging from the worst state imaginable (0) to the best state imaginable (100).

The Shirom Melamed Burnout Questionnaire (SMBQ) has 22 items with responses, graded from 1 to 7 , measuring symptoms such as physical fatigue, tension, emotional exhaustion, listlessness, and cognitive difficulties [30]. High scores indicate more symptoms. The overall burnout index (SMBQ- Global) was obtained by adding together the scores.

A modified version of the Zung Self-Rating Depression Scale (ZSDS) measures the current severity of depressive symptoms [31]. The scale covers affective, psychological, and somatic symptoms. The 23 items have a 4-point response scale, where 1 is equal to "some" and 4 denotes "most of the time". The overall index was calculated by adding together the scores for each item, resulting in a total score of 0-69 in the modified version, where 0 represents no signs of depression.

Quality of sleep was measured with the Karolinska Sleep Questionnaire [32], including the following items: difficulty falling asleep, repeatedly waking up, prematurely waking up, disturbed sleep. The response alternatives range from $6=$ always/everyday, to $1=$ never. Higher scores indicate worse quality of sleep.

The Functional Rating Index (FRI) [33] was used to measure function. The instrument consists of ten items on pain intensity and frequency, sleep, personal care, travelling/driving, ability to work, recreation, lifting, walking and standing. Ratings are made on a 5-point scale. The FRI score is based on calculation of the percentage of total functionality (range 0-100). Higher scores indicate worse functionality.

The Work Ability Index, WAI [34] comprises seven items which take into consideration the demands of work, the worker's health status and resources. For each item a single-item score can be obtained. The final WAI score is the sum of all single-item scores, and ranges from 7 to 49 points, where higher scores indicate better work ability.

\section{Personal resources}

The Pearlin Mastery Scale [35] is a seven-item scale of self-concept and refers to the extent to which individuals perceive themselves in control of forces that significantly affect their lives. Each item consists of a statement with a 4-point response scale. An overall index was calculated 
by adding together the scores, (range 4-28), where higher scores indicate better mastery.

Expectations of RTW were measured by asking the question "In your estimation, what are the chances that you will be working in six months' time?" This question was rated on a 5-point scale, where 1 meant "a very good chance" and 5 meant "very little chance". Scores were dichotomized into high (very good and good chance) and low expectations. Similar questions on expectations for return to work have been used in previous research [36]

Self-efficacy was measured by the Self-Efficacy Scale (SES) [37]. Patients were asked to rate their ability to perform 20 daily activities, despite their pain. The patients rated their ability on an 11 -grade scale, with 0 for "not confident at all to perform the activity" and 10 for "very confident". The total range is 0-200 points, where higher scores indicate better self-efficacy.

Symptom satisfaction was measured with the item "If you had to spend the rest of your life with the condition as it is right now, how would you feel about it?" [38]; higher scores on the 7-point response scale indicate a higher degree of symptom satisfaction.

Social support was measured using the six-item Availability of Social Integration Index (AVSI) [ 39], which deals with social support from family and close friends. The response scale ranges from 1 to 6, where higher scores indicate better social support. Availability of Attachment (AVAT) has six items with responses categorized as "yes" or "no", resulting in a total score ranging between 0 and 6.

\section{Work conditions}

Profession was coded according to the Swedish standard for occupational classification (Statistics Sweden) with nine occupational groups categorized into white-collar (managers, academics, etc.), pink-collar (care, service, salespersons, etc.), and blue-collar (industry, etc.).

Effort-reward imbalance (ERI) at work [40] measures effort based on six items and reward based on 11 items. The effort scores range from 5 to 20 for white-collar, and between 6 and 24 for blue- collar occupations, with high scores indicating high effort. The reward scale ranges from 11 to 44 ; the lower the reward score, the less the perceived reward at work. The ratio of effort/reward indicates imbalance at work when the ERI quota is $\geq 1$.

Overcommitment (OC) was assessed by six items measuring patterns of coping with work demands. The total score for OC ranges from 6 to 24, where a high score indicates that the subject is likely to experience OC at work [41].

Justice was measured with the Moorman Interactional Justice Instrument, which focuses on the interpersonal behaviour of the supervisor and deals with perceptions of fairness in the interactions 
that take place [42]. The instrument consists of six items with a 5-point Likert response scale ranging between 1 and 5, where higher scores indicate higher justice. Scores were averaged into an index. The instrument was translated and psychometrically tested by Liljegren \& Ekberg [43].

Exit behaviour (turnover intentions) was measured using the exit scale in the EVLN instrument modified by Hagedoorn et al. [44], e.g. "considering the possibility of changing jobs". The scale consists of six items with a 7-point Likert response scale. The scores were averaged into an index. The instrument was translated and psychometrically tested by Liljegren et al. [45].

Twenty-two items on the need for workplace adjustments for RTW, e.g. "that you can change working hours", "that your work becomes less stressful". The items were developed and tested in a previous study [46]. In the present study the items were categorized into four indexes, based on a factor analysis (better workplace climate, reduced workplace demands, change of tasks or workplace, reduced physical load and ergonomic tools). Responses were made on a 4-point scale, ranging from "unimportant" to "very important". Scores in each factor were averaged into an index, Cronbach's alpha $=0.65-0.93$.

\section{Register data on sick leave}

Sick leave for each individual was recorded at the Social Insurance Office. This register is established for administrative purposes and not for research. For each individual, the dates for the start and end of sick leave periods were registered during the one-year follow-up period.

\section{Statistical Analyses}

In the analyses, participants who were in employment on the inclusion date and for whom data were available on time to full or partial RTW (n=319) were included. For all instruments, missing data were substituted in each subscale by the median of the responder's score, if responses were given to a predetermined number of items (usually $2 / 3$ of the items) in the subscale. Descriptive statistics are presented as mean and standard deviation of or continuous variables and proportions for categorical variables, to describe the characteristics of the outcome and explanatory variables. Comparisons were made between the two subcohorts (individuals returning to work within 3 months and 3-12 months respectively), using Pearson's $\chi^{2}$-test and Student's $t$-test.

Duration of sick leave was computed as the number of calendar days of absence (full- or parttime) due to sickness within one year from inclusion in the study until the first sustainable ( $>4$ weeks) RTW. Within the four blocks of instruments in the questionnaire: demographic data, health and work ability, personal resources, work conditions and employment situation, a multiple Cox regression analysis was performed to identify which variables were associated with RTW within 3 months, and between 3 and 12 months respectively ( $p<.10)$. The significant predictors from each block were entered into the two final multiple Cox regression analyses, with time to the first 
sustainable (> 4 weeks) RTW as the dependent variable. Data were censored at 365 days. All $p$ values were two-sided and considered to be statistically significant if $\mathrm{p}<.05$ in the final models. All analyses were performed using the statistical software package IBM SPSS Statistics for Windows (version 21.0. Armonk, NY: IBM Corp.)

\section{Results}

\section{Demographics}

In all, $61 \%$ of the responders returned to work within three months and $92 \%$ within 12 months. The demographics of early and later returners were similar. The average age was 44 years (SD 11 years and 10 years respectively) with no difference in sex distribution, occupational code, or in perceived financial strain (Table 1). The educational distribution was roughly similar, with a tendency to a higher proportion of white-collar workers among late returners $(\mathrm{p}=.08)$. A Cox regression analysis was performed within the block of demographic variables. Educational level and financial worries remained associated with RTW in the 3-month subcohort. No demographic variables were associated with RTW in the subcohort of individuals who returned within 3-12 months.

Table 1: Demographics at baseline in the subcohorts of individuals who returned to work within 3 months and 3-12 months of sick leave respectively

There was no major difference in the distribution of diagnoses between returning within 3 months and within 3-12 months: $41 \%$ and $48 \%$ respectively had diagnoses of depression, $15 \%$ and $14 \%$ respectively suffered from anxiety, $39 \%$ and $33 \%$ respectively suffered from stress or burnout according to the medical records; $5 \%$ in both groups had other mental diagnoses.

\section{Health, function and work ability}

Self-rated health, functional ability and work ability are presented in Table 2 . There were significant differences between the two subcohorts in all measures except pain and quality of sleep; early returners had better scores in health measures, work ability and functional ability compared with later returners. In general, self-rated health, function and work ability were at levels indicating a population in comparatively bad health conditions. A Cox regression analysis was performed within the block. Work ability index (WAI) remained associated with RTW in the 3-month subcohort; and EQ-VAS, quality of sleep and FRI remained associated in the subcohort of 
individuals returning within 3-12 months.

Table 2: Self-rated health, functioning, and work ability at baseline in the subcohorts of individuals who returned to work within 3 months and 3-12 months of sick leave respectively

\section{Personal resources}

Symptom satisfaction was significantly more common $(\mathrm{p}=.02)$ among those who returned within three months (Table 3). High expectations of treatment were more prevalent among late returners $(\mathrm{p}=.04)$. In all other measures of personal resources, those who returned within three months were essentially similar in their ratings to those who returned after 3-12 months. A Cox regression analysis was performed within the block. Symptom satisfaction and expectations of recovery from treatment remained associated with RTW in the 3-month subcohort, and selfefficacy in the subcohort of individuals who returned within 3-12 months.

Table 3: Personal resources at baseline in the subcohorts of individuals who returned to work within 3 months and 3-12 months of sick leave respectively

\section{Work conditions}

The Effort-Reward ratio exceeded 1.0 in both groups, indicating a population under high psychosocial stress at work (Table 4). The two groups did not differ in their average ratings of work conditions. A Cox regression analysis was performed within the block of work conditions. Justice and need for reduced demands remained associated with RTW in the 3-month subcohort. In the cohort of individuals returning to work within 3-12 months, associations with RTW remained for occupational categorization (white-, pink- or blue-collar), overcommitment, exit, need for reduced demands and need for reduced physical load

Table 4: Self-rated work conditions at baseline in the subcohorts of 
individuals who returned to work within 3 months and 3-12

months of sick leave respectively

\section{Multiple Cox regression}

Significant variables from multiple Cox regression within each block of predictors were included in the final multiple regression analyses (Table 5). Separate models were performed for the two subcohorts. Lower (i.e. nine-year compulsory school) education (HR=2.4, 95\% C.I. 1.46-3.95), better work ability $(\mathrm{HR}=1.08,95 \%$ C.I. 1.05.1.10), and positive expectations of treatment $(\mathrm{HR}=$ 1.5, 95\% C.I. 1.04-2.16) were associated with early RTW (within three months). At the workplace level, low perceived interactional justice in interaction with supervisors $(\mathrm{HR}=0.83,95 \%$ C.I. 0.71 0.96 ) was associated with return to work within three months. Exit behaviour (HR=1.16, 95\% C.I. 1.01-1.33), or turnover intentions, and need for reduced demands at work (HR=1.64, 95\% C.I. 1.08-2.50) were significantly associated with later RTW.

Table 5: Hazard ratios and 95\% confidence intervals for determinants of RTW in the subcohorts of individuals who returned to work within 3 months and 3-12 months of sick leave respectively

\section{Discussion}

Sick leave due to common mental disorders is an increasing problem in many countries. This study aimed to identify variables associated with sustainable RTW in a cohort of newly sick-listed individuals with common mental disorders. Possible differences between early or late RTW are rarely investigated, despite the fact that long-term sick leave is a risk factor for exclusion from the labour force. Rehabilitation professionals frequently state that there is a need for knowledge on how to distinguish between sick- listed individuals who return to work without requiring active interventions and those who need such interventions early in the process.

We found no differences in RTW between the different diagnoses, while several studies from other countries indicate that there is a difference between different mental diagnoses with regard to duration of sick leave [e.g. 4]. It is conceivable that the diagnostic process may differ between countries due to the different healthcare and social insurance systems. It is also possible that the diagnostic procedure lacks precision, as physicians find it more difficult to determine symptombased diagnoses [47].

Among demographic factors, only educational level was associated with RTW. Higher education, as an estimate of socioeconomic position, was associated with longer sick leave; and lower education was associated with early RTW. A few other studies have found similar associations 
between longer duration of sick leave and higher education [24, 27]; this is in contrast to some other studies [e.g. 26].

The socioeconomic situation may be an important prognostic factor for onset of mental disorders [12]. Lower socioeconomic position increases the risk of sick leave [13], partly because of more physically demanding jobs, and in particular for women [48]. However, duration of sick leave seems partly to depend on other factors than health for employees with common mental disorders. Higher education or better socioeconomic position is often associated with mentally more complex jobs, such as management or expert positions, requiring good mental health and cognitive ability. From an employer perspective, employees in higher positions are also less easily replaced, and may therefore have more support from the employer for long-term recovery before RTW to facilitate return to work with full recovery.

Expected differences were found in all health measures, showing generally worse health, lower functional ability and lower work ability at baseline among those returning later to work. Similarly, Brouwers et al. [16] found that an important predictor of RTW is the severity of the problems. It is apparent that common mental disorders have significant effects on general wellbeing and ability to work, also expressed in terms of reduced work functioning and loss of productivity, and difficulties in meeting the various demands at work [5, 49]. This is supported by the comparably longer periods of sick leave among sick-listed individuals with common mental disorders, compared with several other disorders [7]. However, in spite of the broad battery of health measures, self-rated work ability proved to have the strongest association with RTW among health-related measures. Early and late returners differed in personal resources assumed to facilitate RTW; there was a lower degree of symptom satisfaction among late returners, indicating a negative view of the future development of self-rated disability among late returners. The importance of personal resources is also strengthened by the results regarding expectations of treatment. A higher proportion of positive expectations of treatment among the late returners can be seen as an expression of higher trust in external factors such as treatment, rather than in their own resources. Personal resources are in all likelihood affected by health status, i.e., a higher degree of mental symptoms may lead to a reduction of personal resources and individual agency [49]. High internal demands for performance and perfectionism among employees in career jobs are associated with the onset of mental disorders [50, 51]. In jobs with a higher socioeconomic position, becoming sick-listed with a mental diagnosis may therefore be a greater threat to selfefficacy, symptom satisfaction and other personal resources, compared with other jobs.

Ratings of psychosocial stress, as measured by the ERI ratio, showed that both those who returned after 3 months and those who returned after 3-12 months experienced an imbalance between effort and reward which exceeded 1.0; i.e., a considerable amount of spent effort was not matched by a received reward. Imbalance between effort and reward elicits negative emotions, such as 
injustice, disappointment and sustained stress, and may in the long run lead to increased risk of illness due to strain reactions [41]. The theoretical basis is social reciprocity, i.e. expectations of a mutual give and take between the employer and the employee, based on so-called psychological work contracts [52], representing mutual beliefs, perceptions, and informal obligations between an employer and an employee. Such mutual feelings of trust and loyalty have partly lost their value in today's working life, where employee productivity is strongly emphasised.

When combining the variables of the four blocks of determinants which were associated with RTW into a multiple analysis, a partly unexpected picture emerged. Early RTW was found to be associated with lower education (nine-year compulsory school) and, among the health-related measures, with the work ability index. Regarding measures of personal resources, positive expectations of treatment were associated with early RTW, in spite of more prevalent positive expectations at baseline among late returners. Other health measures had no association with RTW. Among work conditions, worse interactional justice in relation to the supervisor was associated with earlier RTW. Later RTW, i.e. RTW after three months, was associated with higher scores on exit (turnover intentions) and need for reduced demands at work.

The results may be understood in the context of the profound changes that the nature of work and the labour market have undergone during the last decade in Sweden and in other countries. The supervisor is a key player in the interaction between the workplace and the sick-listed employee $[23,53,54]$. The higher degree of experienced injustice in relation to the supervisor among those returning early to work may reflect effects of organizational responses to the increasing demand for flexibility, with new forms of employment contracts leading to looser moral or psychological contracts in the relationship between employer and some workers. Flexible employment contracts and growing demands for competence development have increased insecurity in and about the job. If the relation is strained, the sick-listed worker may find it important to return to work as early as possible to prevent marginalization from the work group, replacement, or termination of her/his employment. The driving force for early RTW is further strengthened by changes in the Swedish Social Insurance System in connection with sick leave, as sick-listed individuals may be given the ultimatum of transferring to another job after three months on sick leave, or be given notice to quit after six months on sick leave. Job instability and the risk of job loss due to sickness absence has become a threat to many people on sick leave; this is reflected in the lower sick leave rates among employees with insecure employment [10]. The need for financial security and continued employment at the workplace is a strong driving force for return to work as early as possible, and in Sweden it is also partly driven by the time limits in Social Insurance System regulations. These behaviours seem to be more pronounced among workers with lower education, who are more easily replaced than workers with a higher education or in leading or expert positions. 
The importance of workplace conditions also emerges in the multivariate model for RTW after three months. Only the work situation and self-rated work ability, but no health measures, were associated with RTW. The results may reflect the worker's own assessment of whether and how her/his work situation and health condition match. In other studies, high turnover intentions have been associated with high workload [55] and job dissatisfaction [56]. Hence, a need for change in the work situation due to too high workload may be a reason for turnover intentions. For workers on long-term sick leave the opportunity to actually change jobs is limited, thus leading to an increased risk of being "locked in". Remaining in a non-preferred employment or being "lockedin" may increase the risk of ill health [57]. The decision and opportunity to actually change jobs is complex and depends on for example socio-demographic factors and unemployment rates [58].

Several studies have shown that the outcome RTW is different from outcomes measuring symptoms, as treatment of symptoms do not necessarily lead to RTW. The results therefore underscore the need for assessment of ability to work, in the context of workplace conditions, rather than merely an assessment of symptoms, independent of work conditions, as is often the case in healthcare.

\section{Study limitations}

In the analyses there was no consideration of changes in degree of sick leave over time. For many sick-listed individuals, the percentage of sick leave may vary (in Sweden, 25\%, 50\%, 75\% or $100 \%$ sick-listing is possible). Changes in degree of sick leave may be frequent and in increasing and decreasing directions, i.e., changes are not necessarily in the direction of step-bystep reductions in degree of sick leave over time. It was therefore not possible to take into consideration changes in degree of sick leave.

Women and early returners were slightly overrepresented among respondents. The differences between early and late returners may therefore be slightly underestimated; however, no differences were found between women and men.

The data collection was performed during the first years after the implementation of stricter regulations in the Social Insurance in Sweden, while there were now changes with regard to employer responsibilities. The stricter regulations were much debated in media and among sicklisted, which may have lead to an increased proneness for early RTW.

In Sweden burnout is an accepted diagnosis for sickness absence, while this is not the case in all jurisdictions. The generalizability of the results to jurisdictions not including burnout as a cause for sickness absence may therefore be questioned. It is however reasonable to assume that patients 
with symptoms of reduced cognitive ability, tiredness, depressive symptoms etc, get related diagnoses as mood disorders, depression or anxiety in other jurisdictions. Also in Sweden physicians may choose these diagnoses, i.e. there is a grey zone in diagnostics with regard to symptom diagnoses. Since the various diagnoses mentioned most likely are classified among common mental disorders, it is likely that the results are generalizable.

\section{Conclusions}

This study shows that early RTW among sick-listed individuals with common mental disorders is less associated with health and symptoms, and more with the employee's position and the workplace. Those who returned to work within three months had on average better health, functioning and personal resources, but these factors were of less importance for RTW than relations with the supervisor. Job insecurity and risk of marginalisation seem to be driving forces for early RTW, while late RTW seems to depend on dissatisfaction with the workplace and the need for workplace adjustments. The study highlights the importance of considering workplace conditions, the need for workplace adjustments, and relations at the workplace, when assessing work ability and implementing RTW interventions.

\section{Conflict of interest}

Author Kerstin Ekberg declares that she has no conflict of interest.

Author Charlotte Wåhlin declares that she has no conflict of interest.

Author Jan Persson declares that he has no conflict of interest.

Author Lars Bernfort declares that he has no conflict of interest.

Author Birgitta Öberg declares that she has no conflict of interest.

\section{Informed consent}

All procedures followed were in accordance with the ethical standards of the responsible committee on human experimentation (institutional and national) and with the Helsinki Declaration of 1975, as revised in 2000. Informed consent was obtained from all patients for being included in the study.

\section{Acknowledgements}


We thank Henrik Magnusson for skilful statistical analyses. The study was supported by the

Swedish Research Council for Health, Working Life and Welfare (FORTE), and the County Council of Ostergotland, Sweden. 


\section{References}

1. Social Insurance in Figures. Stockholm, Social Insurance Office 2004.

2. Hensing G, Spak F. Psychiatric disorders as a factor in sick leave due to other diagnoses: a general populations-based study. Br J Psychiatry 1998;172:250-6

3. Nystuen P, Hagen KB, Herrin J. Mental health problems as a cause of sick leave in the Norwegian work force. Scand J Public Health 2001;29:175-82.

4. Roelen CAM, Norder G, Koopmans PC, van Rhenen W, van der Klink JJL, Bültmann U. Employees sick-listed with mental disorders: Who returns to work and when? J Occup Rehabil 2012;22:409-4017.

5. OECD. Sick on the job? Myths and realities about mental health at work. 2011. http://www.oecd.org/els/emp/sickonthejob2011.htm.

6. Goetzel RZ, Ozminkowski RJ, Sederer LI, Mark TL. The business case for quality mental health services: why employers should care about the mental health and well-being of their employees. J Occup Environ Med. 2002;44:320-30.

7. Lagerveld SE, Bültmann U, Francche RL, van Dijk FJH, Vlasveld MC, van der Feltz-Conelis CM, Bruinvels DJ, Huijs JJJM, Blonk RWB, van der Klink JJL, Nieuwenhuijsen K. Factors associated with work participation and work functioning in depressed workers: A systematic review. J Occup Rehabil 2010;20:275-292.

8. Taloyan M, Aronsson G, Leineweber C, Magnusson Hansson L, Alexandersson K, Westerlund H. Sickness presenteeism predicts suboptimal self-rated health and sickness absence: A nationally representative study of the Swedish working population. PLOS ONE 2012;9:e44721.

9. Sverke M, Hellgren J, Näswall K. No security: a meta-analysis and review of job insecurity and its consequences. J Occup Health Psychology 2001;7:242-64.

10. Virtanen M, Kawachi I, Oksanen T, Salo P, Tuisko K. et el. Socioeconomic differences in long term psychiatric work disability: prospective cohort study of onset, recovery and recurrence. Occup Environ Med 2011;68:791-798.

11. Semmer NK, Tscan F, Maier LL, Facchin S, Jacobshagen N. Illegitimate tasks and counterproductive work behavior. Applied Psychology 2010;59:70-96.

12. Nieuwenhuijsen K, Bruinvels D, Frings-Dresen M. Psychosocial work environment and stress-related disorders, a systematic review. Occup Med 2010;60:277-286.

13. Rugulies R, Aust B, Madsen IEH, Burr H, Siegrist J, Bültmann U. Adverse psychosocial working conditions and risk of severe depressive symptoms. Do effects differ by occupational grade? Eur J Public Health 2012;23:415-420.

14. Borritz M, Christensen KB, Bultmann U, Rugulies R, Lund T, Andersen I, Villadsen E, Diderichsen F, Kristensen TS. Impact of Burnout and Psychosocial Work Characteristics on Future Long-Term Sickness Absence. Prospective Results of the Danish PUMA Study Among Human Service Workers. J Occ Environ Med. 2010; 52(10):964-970. 
15. Zapf D. Organisational, work group related and personal causes of mobbing/bullying at work. International Journal of Manpower 1999;20:70-85.

16. Brouwers EPM, Terluin B, Tiemens BG, Verhaak PFM. Predicting return to work in employees sick-listed due to minor mental disorders. J Occup Rehabil 2009;19:323-332.

17. Knudsen AK, Harvey SB, Mykletun A, Ǿverland S. Common mental disorders and long-term sickness absence in a general working population. The Hordaland Health Study. Acta Psychiat Scand 2013;127:287-297.

18. Van der Klink JJ, Blonk RW, Schene AH, van Dijk FJ. Reducing long term sickness absence by an activating intervention in adjustment disorders: a cluster randomized controlled design Occup Environ Med 2003;60:429-37

19. Furlan AD, Gnam WH, Carnide N, Irvin E, Amick III BC, De Rango K, et al. Systematic review of intervention practices for depression in the work place. Canada, Institute of Work and Health, February 2011. http://www.iwh.on.ca/sys-reviews/workplace-depressioninterventions

20. Wåhlin C, Ekberg K, Persson J, Bernfort L, Öberg B. Association between clinical and workrelated interventions and return-to-work for patients with musculoskeletal or mental disorders. J Rehabil Med 2012:44;355-362

21. Loisel P, Durand P, Abenhaim L, et al. Management of occupational back pain: The Sherbrooke model. Results of a pilot and feasibility study. Occup Environ Med 1994;51:597602.

22. Andersen MF, Nielsen KM, Brinkmann S. Meta-synthesis of qualitative research on return to work among employees with common mental disorders. Scand J Work Environ Health 2012; 38:93-104.

23. Virtanen P, Vahtera J, Nakari R, Pentti J, Kivimäki M. Economy and job contract as contexts of sickness absence practices: revisiting locality and habitus. Soc Sci Med 2004;58:12191229.

24. Post M, Krol B, Groothoff JW. Work-related determinants of return to work of employees on long-term sickness absence. Disabil Rehabil 2005;27:481-488.

25. Arends I, van der Klink JCL, van Rhenen W, de Boer MR, Bültmann U. Prevention of recurrent sickness absence in workers with common mental disorders: results of a clusterrandomised controlled trial. Occup Environ Med 2014;71:21-29.

26. Ervasti J, Vahtera J, Pentti J, Oksanen T, Ahola K, Kivimäki M, Virtanen M. Depressionrelated work disability: Socioeconomic inequalities in onset, duration and recurrence. PLOS One 2013;8:e79855-

27. Nieuwenhuijsen K, Verbeek JHAM, de Boer AGEM, Blonk RWB, van Dijk FJH. Predicitng the duration of sickness absence for patients with common mental disorders in occupational health care. Scand J Work Environ Health 2006;32:67-74.

28. Dolan P, Gudex C, Kind P, Williams A. Modeling Valuations for EuroQol Health States. Medical Care.1997;35:1095-1108.

29. The EuroQol Group. EuroQol - a new facility for the measurement of health related quality of life. Health Policy 1990;16:199-208.

30. Shirom A, Melamed S, Toker S, Berliner S, Shapira I. Burnout and health review: current 
knowledge and future research directions. In: Hodgkinson GP, Ford JK, editors. International review of industrial and organizational psychology. Vol. 20. Palo Alto, CA: Consulting Psychologists Press; 2005, p. 269-309.

31. Main CJ, Wood PL, Hollis S, Spanswick CC, Waddell G. The distress and risk assessment method. Spine 1992;17:42-52.

32. Åkerstedt T, Knutsson A, Westerholm P, Theorell T, Alfredsson L, Kecklund G. Sleep disturbances, work stress and work hours. A cross-sectional study. J. Psychosom. Res. 2002; 53: 741-748.

33. Feise RJ, Menke JM. Functional Rating Index. A new valid and reliable instrument to measure the magnitude of clinical change in spinal conditions. Spine 2001;26;78-87.

34. Tuomi K, Ilmarinen J, Jahkola A, Katajarinne L, Tulkki A. Work ability index. Helsinki: Finnish Institute of Occupational Health; 1994.

35. Pearlin LI, Lieberman MA, Menaghan EG, Mullan JT. The stress process. J Health Soc Behav. $1981 ; 22: 337-56$.

36. Lambeek LC, van Mechelen W, Buijs PC, Loisel P, Anema JR. An integrated care program to prevent work disability due to chronic low back pain: a process evaluation within a randomized controlled trial. BMC Musculoskelet Disord, 2009. 10: 147.

37. Altmaier E, Russell D, Kao C, Lehmann T, Weinstein J. Role of self-efficacy in rehabilitation outcome among chronic low back pain patients. J of Counseling Psychology 1993;40:335-339.

38. Cherkin DC, Deyo RA, Street JH, Barlow W. Predicting poor outcomes for back pain seen in primary care using patients' own criteria. Spine 1996;21:2900-2907.

39. Undén AL, Orth-Gomér K. Development of a social support instrument for use in population surveys. Soc Sci Med 1989;29:1387-1392

40. Siegrist J, Wege N, Puhlhofer F, Wahrendorf M. A short generic measure of work stress in the era of globalization: effort-reward imbalance. Int Arch Occup Environ Health. 2009; 82:1005-13.

41. Siegrist J, Starke D, Chandola T, Godin I, Marmot M, Niedhammer I, Peter R. The measurement of effort-reward imbalance at work: European comparisons. Soc Sci Med 2004; 58:1483-1499.

42. Moorman R H. "Relationship between organizational justice and organizational citizenship behaviors: Do fairness perceptions influence employee citizenship? J Appl Psychol 1991; 76: 845-855

43. Liljegren M, Nordlund A, Ekberg K. Psychometric evaluation and further validation of the Hagedoorn et al. modified EVLN measure. Scand J Psychol. 2008;49:169-77.

44. Hagedoorn M, van Yperen N, van der Vliet E, Buunk B. Employees' reactions to problematic events: a circumplex structure of five categories of responses, and the role of job satisfaction. J Organ Behav. 1999; 20:309-321.

45. Liljegren M, Ekberg K. Job mobility as predictor of health and burnout. J Occup Organ Psychol. 2009; 82:317-329

46. Strindlund L, Ekberg K. Långtidssjukskrivna inom Landstinget i Östergötland 2002. Diagnoser, arbetsförhållanden och rehabiliteringsbehov. Linköpings universitet, IHS-rapport 2004:1 (In 
Swedish).

47. Nilsing E, Söderberg E, Berterö C, Öberg B. Primary healthcare professionals' experiences of the sick leave process: A focus group study in Sweden. J Occup Rehabil 2013: 23:450-61

48. Löve J., Hensing G., Holmgren K., Torén K. (2013). Explaining the social gradient in sickness absence: a study of a general working population in Sweden BMC Public Health 13:545

49. Bertilsson M. Work capacity and mental health - the phenomena and their importance in return to work. Dissertation. Institute of Medicine at Sahlgrenska Academy, University of Gothenburg. 2014.

50. Sandmark H, Renstig M. (2010) Understanding long-term sick leave in female white-collar workers with burnout and stress-related diagnoses: a qualitative study. BMC Public Health. 10(1):210.

51. Holmgren K, Dahlin Ivanoff S. (2004) Women on sickness absence--views of possibilities and obstacles for returning to work. A focus group study. Disabil Rehabil. 2004;26:213-22.

52. Argyris C. Understanding organizational behavior. Michigan, Dorsey Press. 1960.

53. Nieuwenhuijsen K, Verbeek JHAM, de Boer AGEM, Blonk RWB, van Dijk FJH. Supervisory behaviour as a predictor of return to work in employees absent from work due to mental health problems. Occup Environ Med 2004;61:817-823.

54. Lemieux P, Durand M-J, Nha Hong Q. Supervisors' perception of the factors influencing the return to work of workers with common mental disorders. J Occup Rehabil 2011;21:293-303.

55. Conklin MH, Desselle SP. Job turnover intentions among pharmacy faculty. Am J Pharm Educ 2007;71:62

56. Coomber B, Barriball KL. Impact of job satisfaction components to leave and turnover for hospital-based nurses: a review of job-related and non-related factors. Int J Nurs Stud. 2007;44:297-314.

57. Aronsson G, Göransson S. Permanent employment hut in a non-preferred occupation: psychological and medical aspects, research and implications. J Occup Health Psych. 1999:4:152-163

58. Wilk SL, Sackett PR. Longitudinal analysis of ability-job complexity fit and job change. Pers Psychol 1996;49:937-967. 
Table 1: Demographics at baseline in the subcohorts of individuals who returned to work within 3 months and 3-12 months of sick leave respectively

\begin{tabular}{|c|c|c|c|c|c|}
\hline & \multicolumn{2}{|c|}{$\begin{array}{c}\text { RTW } \\
<3 \text { months } \\
\text { N=195 }\end{array}$} & \multicolumn{2}{|c|}{$\begin{array}{c}\text { RTW } \\
\text { 3-12 months } \\
\text { N=98 }\end{array}$} & \multirow[t]{2}{*}{$\mathbf{p}$} \\
\hline & $\mathrm{n}$ & $\%$ & $\mathrm{n}$ & $\%$ & \\
\hline \multicolumn{6}{|l|}{ Sex } \\
\hline Female & 157 & 80 & 84 & 86 & \\
\hline Male & 38 & 20 & 14 & 14 & .272 \\
\hline \multicolumn{6}{|l|}{ Education } \\
\hline $\begin{array}{l}\text { Compulsory school } \\
\text { (nine years) }\end{array}$ & 24 & 12 & 5 & 5 & \\
\hline $\begin{array}{l}\text { Upper secondary } \\
\text { school }\end{array}$ & 98 & 50 & 45 & 47 & \\
\hline University & 73 & 37 & 46 & 48 & .077 \\
\hline Financial strain, yes & 55 & 28 & 36 & 37 & .129 \\
\hline \multicolumn{6}{|l|}{ Occupational code } \\
\hline White & 77 & 40 & 47 & 49 & \\
\hline Pink & 89 & 46 & 34 & 35 & \\
\hline Blue & 29 & 15 & 16 & 17 & .216 \\
\hline
\end{tabular}

Note: Information on educational level was missing for two persons and information on occupation was missing for one person. 
Table 2: Self-rated health and work ability at baseline in subcohorts of individuals who returned to work within 3 months and 3-12 months of sick leave respectively

\begin{tabular}{|l|l|l|l|l|l|}
\hline & \multicolumn{2}{|c|}{$\begin{array}{r}\text { RTW } \\
\text { N=195 months }\end{array}$} & \multicolumn{2}{c|}{$\begin{array}{c}\text { RTW months } \\
\text { N=98 }\end{array}$} & \\
\hline & m & sd & m & sd & \\
\hline EQ-5D & 0.56 & 0.26 & 0.48 & 0.27 & .017 \\
\hline EQ-VAS & 51.95 & 20.30 & 45.20 & 17.64 & .005 \\
\hline Melamed burnout, SMBQ & 4.98 & 1.03 & 5.39 & 0.97 & .001 \\
\hline $\begin{array}{l}\text { Zung Depression Scale, } \\
\text { ZSDS }\end{array}$ & 34.13 & 9.47 & 36.23 & 8.27 & .054 \\
\hline Pain-VAS & & & & & \\
\hline Quality of sleep & 22.04 & 24.96 & 24.59 & 24.14 & .417 \\
\hline Functional Rating Index, FRI & 3.27 & 1.20 & 3.03 & 1.26 & .111 \\
\hline WAI index & 27.57 & 16.58 & 32.23 & 15.81 & .024 \\
\hline & 28.19 & 6.95 & 24.73 & 6.68 & $<.001$ \\
\hline
\end{tabular}


Table 3: Personal resources at baseline in subcohorts of individuals who returned to work within 3 months and 3-12 months of sick leave respectively

\begin{tabular}{|l|c|c|c|c|c|}
\hline & \multicolumn{2}{|c|}{$\begin{array}{c}\text { RTW } \\
\text { < } 3 \text { months }\end{array}$} & \multicolumn{2}{c|}{$\begin{array}{c}\text { 3-12 months } \\
\text { N=195 }\end{array}$} & \multicolumn{2}{c|}{ N=98 } & \\
\hline & Mean & sd & mean & sd & \\
\hline Self-efficacy & 150.45 & 41.44 & 144.31 & 44.34 & .259 \\
\hline Mastery & 19.38 & 3.69 & 19.62 & 3.52 & .590 \\
\hline AVAT & 5.27 & 1.34 & 5.38 & 1.20 & .498 \\
\hline AVSI & 19.11 & 5.26 & 20.01 & 5.48 & .182 \\
\hline & $\mathrm{n}$ & $\%$ & $\mathrm{n}$ & $\%$ & \\
\hline $\begin{array}{l}\text { Symptom satisfaction, \% } \\
\text { satisfied }\end{array}$ & 36 & 19 & 8 & 8 & .021 \\
\hline $\begin{array}{l}\text { Expectation of RTW, \% } \\
\text { high }\end{array}$ & 156 & 81 & 79 & 81 & .968 \\
\hline $\begin{array}{l}\text { Expectations of treatment, } \\
\text { \% high }\end{array}$ & 150 & 79 & 86 & 89 & .035 \\
\hline
\end{tabular}


Table 4: Self-rated work conditions at baseline in subcohorts of individuals who returned to work within 3 months and 3-12 months of sick leave respectively

\begin{tabular}{|c|c|c|c|c|c|}
\hline & \multicolumn{2}{|c|}{$\begin{array}{c}\text { RTW } \\
<3 \text { months } \\
\mathrm{N}=195\end{array}$} & \multicolumn{2}{|c|}{$\begin{array}{c}\text { RTW } \\
\text { 3-12 months } \\
\mathrm{N}=98\end{array}$} & \multirow[t]{2}{*}{$\mathbf{p}$} \\
\hline & mean & $\mathrm{sd}$ & mean & sd & \\
\hline Effort-reward index & 1.13 & 0.48 & 1.11 & 0.36 & .663 \\
\hline Overcommitment & 15.71 & 4.51 & 16.55 & 4.30 & .131 \\
\hline Justice & 3.55 & 1.09 & 3.77 & 0.85 & .087 \\
\hline Physical load & 12.55 & 3.36 & 12.42 & 3.11 & .745 \\
\hline Exit behaviour & 3.94 & 1.51 & 3.85 & 1.55 & .653 \\
\hline Great need for: & $\mathrm{n}$ & $\%$ & $\mathrm{n}$ & $\%$ & \\
\hline Better work climate, $\%$ & 81 & 43 & 45 & 47 & .518 \\
\hline Reduced demands, $\%$ & 91 & 49 & 52 & 55 & .357 \\
\hline Change of workplace, $\%$ & 54 & 29 & 20 & 21 & .166 \\
\hline Reduced physical load, \% & 36 & 19 & 17 & 18 & .798 \\
\hline
\end{tabular}


Table 5: Hazard ratios and 95\% confidence intervals for determinants of RTW in subcohorts of individuals who returned to work within 3 months and 3-12 months of sick leave respectively

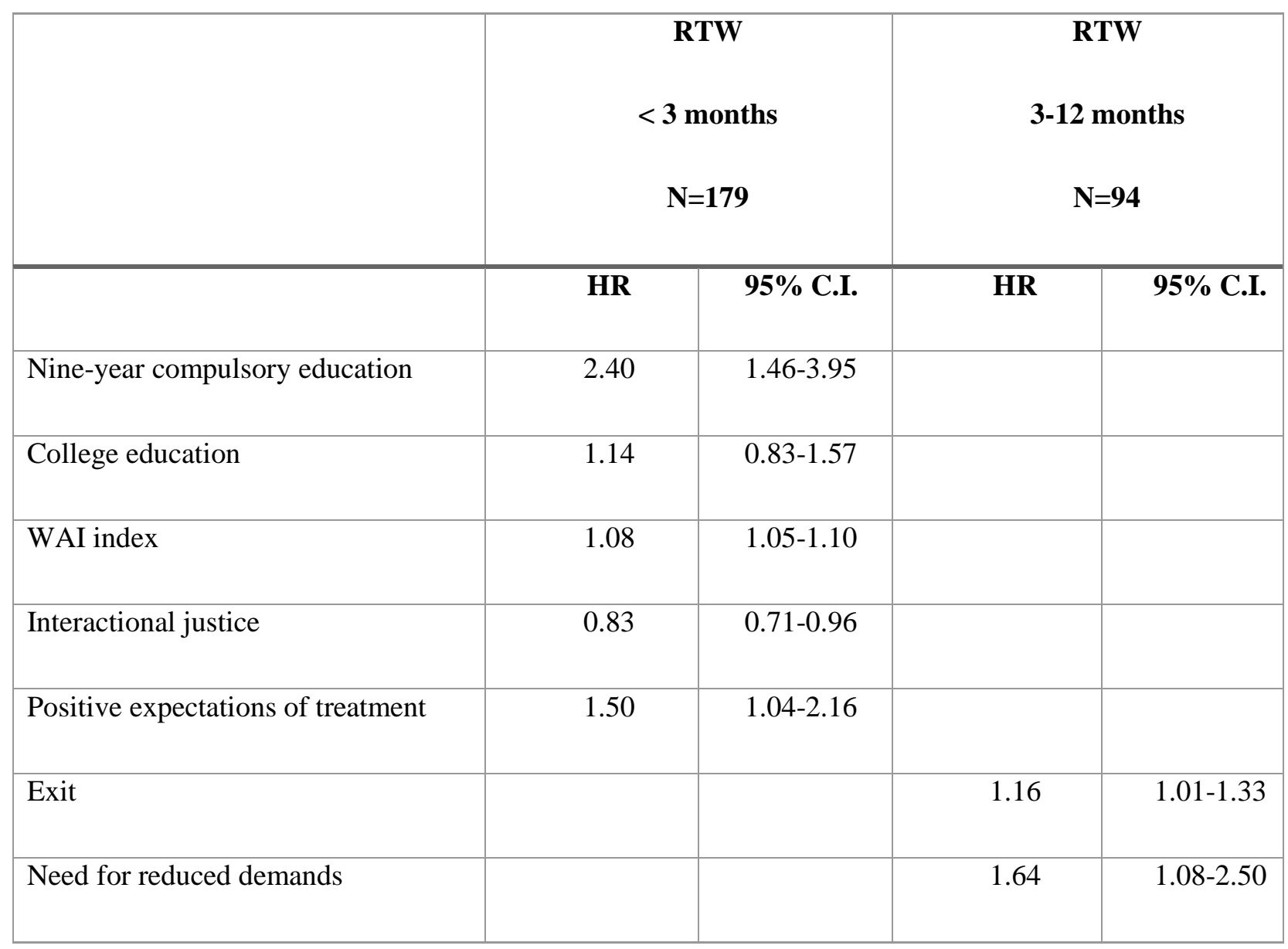

